\title{
Design and Characterization of Maltose-Conjugated Polycaprolactone Nanofibrous Scaffolds for Uterine Tissue Engineering
}

\author{
Srividya Hanuman ${ }^{1} \cdot$ Manasa Nune $^{1}$ (D)
}

Received: 14 June 2021 / Revised: 28 August 2021 / Accepted: 13 September 2021 / Published online: 1 October 2021

(c) The Author(s) 2021

\begin{abstract}
Purpose Uterine anomalies are prevalent in women, and the major treatment assisted to them is hysterectomy as donor availability is extremely low. To overcome this, engineering uterine myometrium smooth muscle tissue has become very important. Several studies have shown that polycaprolactone (PCL) nanofibers are very effective in engineering smooth muscles, as this type of scaffold has structural similarities to the extracellular matrices of the cells. Here, we hypothesize that by electrospinning PCL nanofibers, they form a suitable scaffold for uterine tissue engineering.

Methods Polycaprolactone nanofibrous scaffolds were fabricated, and surface modification was performed following two step wet chemistry method. First step is aminolysis which introduces the primary amine groups on the PCL scaffolds following which maltose is conjugated on the scaffolds. This was confirmed by the ninhydrin assay for the presence of amine groups. This was followed by ELLA assay where the presence of maltose on the scaffold was quantified. Modified scaffolds were further characterized by scanning electron microscope (SEM), contact angle analysis and Fourier transform infrared spectroscopy (FTIR). MTT assay, live-dead assay and actin staining were performed on the maltose immobilization to study the improvement of the cell attachment and proliferation rates on the modified scaffolds.

Results Human uterine fibroblast (HUF) cells displayed significant proliferation on the maltose-modified PCL scaffolds, and they also exhibited appropriate morphology indicating that these modified fibers are highly suitable for uterine cell growth. Conclusion Our results indicate that the fabricated maltose PCL (MPCL) scaffolds would be a potential biomaterial to treat uterine injuries and promote regeneration.

Lay Summary and Future Work Uterine anomalies are prevalent in women, and the major treatment is hysterectomy as donor availability is extremely low. Over the past few years, considerable efforts have been directed towards uterine tissue regeneration. This study is to design a tissue engineered scaffold that could act as a human uterine myometrial patch. We propose to create uterine fibroblast-based synthetic scaffolds that act in a condition similar to the intrauterine microenvironment where the embryos are embedded in the uterine wall. For understanding of the efficiency of the myometrial patch, functional characterization will be performed to study the effects of estrogen and prostaglandins on myometrial activity of the designed patch. Results from these experiments will assist a deeper understanding of how to construct a total bioengineered uterus which can substitute the uterus transplantation procedure, which nonetheless is in its initial stages of development.
\end{abstract}

Keywords Uterine tissue repair · Electrospinning $\cdot$ Polycaprolactone $\cdot$ Maltose conjugation $\cdot$ Human uterine fibroblasts

\section{Introduction}

Uterus is a muscular organ consisting of the fundus, corpus and cervix. Anatomically it is positioned between the urinary bladder anteriorly and rectum posteriorly. An adult

Manasa Nune

manasa.nune@manipal.edu

1 Manipal Institute of Regenerative Medicine, Bengaluru, Manipal Academy of Higher Education, Manipal, Karnataka, India uterus is approximately $6-9 \mathrm{~cm}$ long, $5 \mathrm{~cm}$ across, $4 \mathrm{~mm}$ in thickness with an average volume of $80 \mathrm{ml}$ to $200 \mathrm{ml}$ [1].

The uterine and ovarian arteries supply blood to the uterus; the uterine arteries being the main source of blood supply. They branch into arcuate and radial arteries when 
they enter the myometrium and the endometrium, and they branch into basal and spiral arteries. These arteries play an important role in maintaining blood supply during menstrual cycles and pregnancy [1]. Studies show that due to multifactorial reasons, about 3\% to 5\% of women suffer from absolute uterine factor infertility (AUFI) [2]. It is seen that approximately $30 \%$ of women in the world suffer from Mullerian malformations. As mentioned earlier, the acquired anomalies that a female suffers from are of several kinds. Of these disorders, $13 \%-50 \%$ are polyps, out of which $1.0 \%$ turn malignant [2]. Of the women, $2-17 \%$ in their reproductive years suffer from endometriosis [3]. It is seen that approximately $80 \%$ of women with abnormal uterine conditions suffer from adenomyosis.

As most of the administered medications are not very effective in treating the anomalies and have long-term side effects due to prolonged use of steroids, surgeries like uterine fibroid embolization, myomectomy, endometrial ablation and hysterectomy are being performed. But they come with the disadvantages such as not being able to conceive, damage to surrounding tissues, excess blood loss and infection. By studies we know that $6 \%$ of women in India and around $20 \%$ around the world undergo hysterectomy every year [4]. The scarcity of uterine donors makes it extremely hard to perform uterine transplantations. Therefore, uterine tissue engineering is a novel technique to repair or engineer uterine tissues.

Many tissue engineering techniques involve cells obtained from tissues, seeded on scaffolds fabricated using an appropriate biomaterial [5]. These materials mimic the biological and mechanical function of the native extracellular matrix (ECM) therefore acting as an artificial ECM. Biomaterials provide a platform for the cells to attach and to form new tissues with suitable structure and functions. These also permit the delivery of cells and bioactive factors to selected locations in the body. Cell-adhesion peptides, growth, and bioactive factors can be inserted along with the cells to regulate cellular functions [5]. These materials also provide mechanical strength against the in vivo forces and ensure that the structure of an organ is maintained during tissue development.

An ideal biomaterial is biodegradable and bioresorbable, to avoid inflammation and to engineer normal tissues. However, this depends on the tissue of interest. Materials that are incompatible induce inflammatory or immunological responses leading to necrosis or even rejection. Products that are produced, in case of degradation should be removed from the body following metabolic pathways to maintain the concentration of these products in the tissues at a tolerable level. The biomaterial should also provide an environment which provides proper regulation of cell behaviour such as adhesion, proliferation, migration and differentiation to form functional tissues. Therefore, biomaterials provide temporary mechanical support till the cells reorganize into tissues. The biomaterials need to be chosen in such a way that they promote the engineered tissue to have sufficient mechanical integrity to support itself during the initial days of development and begin to degrade in the later stages so as to not hinder tissue growth [5].

PCL is a semi-crystalline, biodegradable and non-toxic polyester used for the fabrication of scaffolds for smooth muscle engineering. The myometrial specimen's elastic modulus (45 to $60 \mathrm{MPa}$ ) [6] is similar to electro-spun PCL fiber whose total elastic modulus is $\sim 60 \mathrm{MPa}$ making it an ideal biomaterial for uterine engineering [7]. Its melting point is at $55-60{ }^{\circ} \mathrm{C}$ and glass transition temperature $\left(60^{\circ} \mathrm{C}\right)$ and is soluble in a wide range of organic solvents [8]. However, the main disadvantage is its hydrophobicity and slow degradation rate. PCL has been known to remain in situ up to a span of 24 months. These problems can be addressed by blending it with different polymers or modifying the surface of the scaffold to increase hydrophilicity. Studies have shown that the surface modified scaffolds enhance cellular adhesion, proliferation and differentiation in both in vitro and in vivo conditions.

The surface of the degradable and non-biodegradable synthetic nanofibers is modified using active biomolecules for therapeutic applications. It is easier to process synthetic polymers by electrospinning which helps in controlling nanofiber morphology than in natural polymers. Natural polymers are mostly water soluble making it difficult to process them into nanofibers directly, due to their unstable nature and are also vulnerable to harsh processing conditions as they are mechanically weak. On the other hand, the synthetic polymers are of various types and can be used for specific biological functions with desirable properties [9]. These biologically modified synthetic nanofibers improve cell specificity and retain organization, as the tissue regeneration process involves complex biochemical signals present on the cell adhesion surface. The electrospun nanofiber mesh is an ideal condition for sustained and local drug delivery due to highly interconnected open nanoporous structure with high surface area. There are several surface modification techniques that can be used in synthetic polymer nanofibers for tissue engineering [10].

Maltose is a disaccharide made up of two alpha $\mathrm{D}$ glucose in which carbon 1 of the first glucose molecule is bonded to carbon 4 of second glucose molecule alpha 1,4 glycosidic linkage. The presence of different carbohydrates in the uterus has been studied for a very long time [11]. The role of maltose in penetration of the ovum by the sperm is known. Therefore, we want to explore the importance and role of maltose in the ECM remodeling and application towards uterus tissue engineering. The wettability of the surface of a scaffold can be increased by modifying the surface of the biodegradable aliphatic polyester films by 
hydrolysis using acidic or basic conditions. Plasma treating the nanofibrous mesh is not effective to modify the surface of the buried fibers as the penetration of plasma through nanopores is less. Therefore, introducing chemicals by wet methods is preferred as it offers flexibility to modify the surface of thick scaffold meshes. By following an aminolysis method, diamine groups are used to generate functionalized amine surfaces by introducing positive charges. Electro-spun poly (L-lactide-cocaprolactone) nanofibrous scaffolds were surface-modified by aminolysis and were followed by neoglycosylation [12]. The aminolysed scaffolds are treated with $\alpha$-glucoside residues with controlled orientation of carbohydrate moieties [13].

\section{Materials and Methods}

\section{Materials}

Polycaprolactone was purchased from Sigma (MW 80,000); Methanol, Chloroform and Dimethyl sulfoxide were purchased from HiMedia; Phosphate Buffer Saline tablets were purchased from Sigma Life science; Live/Dead reagent (lot no. 2015555) and, Rhodamine-Phalloidin (lot no. 2157163) were purchased from Invitrogen, MTT (TC1911G), and DAPI (4',6 Diamidino-2-phenylindole dihydrochloride) (MB097-10MG) was purchased from HiMedia and Fibroblast Growth Kit-low Serum- (ATCC® PCS201-041 from ATCC, USA.

\section{Fabrication of PCL Nanofibers}

$10 \%(\mathrm{w} / \mathrm{v})$ PCL solution was prepared in 8:2 ratios of chloroform and methanol. The solution was loaded into a 5-ml glass syringe of needled size 24G. Nanofibers were synthesized at a flow rate of $0.002 \mathrm{ml} / \mathrm{min}$ at an applied voltage of $18 \mathrm{kV}$ using electrospinning machine (HO-NFES-040). The nanofiber mats obtained were stored in vacuum desiccator for further characterization.

\section{Surface Modification of Nanofibers}

The fabricated PCL nanofibers were surface modified by two step wet chemistry method. For amine grafting the PCL discs were soaked overnight at $37^{\circ} \mathrm{C}$ in $10 \% 1,6$-hexane diamine made in $10 \mathrm{ml}$ isopropanol. These scaffolds were later washed with distilled $\mathrm{H}_{2} 0$ and air-dried. Later neo-glycosylation was performed to conjugate maltose on the aminated scaffolds. The aminated discs were soaked in a citrate buffer solution of $(\mathrm{pH}=6.1,5 \mathrm{ml}), 1.046 \mathrm{~g}$ of maltose, and $95 \mathrm{mg}$ of sodium cyanoborohydride $(\mathrm{NaBH} 3 \mathrm{CN})$ overnight. These were thoroughly rinsed in distilled water.

\section{Physicochemical Characterization of the Modified Scaffolds}

1) Contact angle analysis: The hydrophilicity was measured for electro-spun PCL, aminolysed (APCL), and maltose PCL (MPCL) discs using a goniometer. Approximately similar volumes of deionized water were carefully placed on the surface of the discs. The contact angles were measured by taking two samples of each type and placing them at 3 different positions. Values for PCL were hydrophobic $\left(>90^{\circ}\right)$, whereas both aminolysed and maltose-modified PCL showed hydrophilic characteristics.

2) Ninhydrin assay: The presence of amine groups was quantified using the ninhydrin assay. The scaffold discs of $n=3$ were put in glass test tubes with ninhydrin reagent $(1 \mathrm{M})$ prepared using $1.7 \mathrm{~g}$ of ninhydrin in $10 \mathrm{ml}$ ethanol. The aminolysed and non-aminolysed discs were incubated in $100 \mu$ l of ninhydrin solution in hot water at $70^{\circ} \mathrm{C}$ for $15 \mathrm{~min}$. These tubes were kept out till they reached room temperature. Followed by adding $500 \mu \mathrm{l}$ of chloroform and isopropanol to the tubes for dissolving the scaffolds of which $100 \mu \mathrm{l}$ was added to 96 well plates and the intensity was measured in $562 \mathrm{~nm}$. Negative control was kept using a blank test tube that had no scaffold.

3) Enzyme-linked lectin assay: For quantifying the presence of carbohydrate moieties, Enzyme-Linked Lectin Assay (ELLA) was performed. The PCL, aminolysed (APCL) and maltose PCL (MPCL) samples of $n=3$ were treated with $2 \%$ BSA solution for $14 \mathrm{~h}$ at $5{ }^{\circ} \mathrm{C}$ on the rocker. Later the discs were removed and incubated at room temperature in a solution of the lectin from Arachis hypogea (peanut) peroxidase (Sigma-Aldrich, catalogue $\mathrm{n}$ L7759) $(0.01 \mathrm{mg} / \mathrm{mL}, 200 \mu \mathrm{l})$ for $2 \mathrm{~h}$ on the rocker. The discs films were then thoroughly washed using PBS to remove the unbound lectin and were later treated with o-phenylenediamine dihydrochloride (SIGMAFASTM OPD, Sigma-Aldrich, catalogue n P9187) $(500 \mu \mathrm{l}, 1 \mathrm{~h}) .100 \mu \mathrm{l}$ of this solution was taken into a 96 well plate and the absorbance was measured at $450 \mathrm{~nm}$.

4) FTIR analysis: The surface modification was confirmed by FTIR. FTIR spectroscopy with attenuated total reflection (ATR) sampling technique (Frontier PerkinElmer) was carried out to determine the amine group and maltose on the surface of PCL nanofibers. All the spectra presented are the average of 128 scans in the wavelength 
range of $4000-650 \mathrm{~cm}^{-1}$, and the data were plotted as percentage transmittance against wave number $\left(\mathrm{cm}^{-1}\right)$.

\section{Culturing of Human Uterine Fibroblasts}

Human uterine fibroblasts were procured from (ATCC $®$ PCS460010 ${ }^{\mathrm{TM}}$ ) were cultured in Fibroblast basal medium (ATCC-PCS-201-030) growth media with Fibroblast Growth Kit-low Serum- (ATCC® PCS-201-0410) and $1 \%$ penicillin-streptomycin and maintained at $37{ }^{\circ} \mathrm{C}$ in $5 \%$ carbon dioxide. Confluent human uterine fibroblasts were cultured and were seeded on surface-modified scaffolds for further studies.

\section{Biological Characterization of the Modified Scaffolds}

\section{1) Cell Seeding on Scaffolds}

The elctrospun PCL nanofibers were sterilized for 2-3 h in UV for each side. PCL, aminolysed PCL (APCL) and maltose PCL (MPCL) scaffolds were placed in a 48 well plate. About 50,000 cells were seeded for cell adhesion and proliferation studies and 10,000 cells seeded for microscopic studies. Tissue culture polystyrene (TCPS) was used as control, and the growth medium was changed every other day.

\section{2) Cell Adhesion and Proliferation}

The cell proliferation and viability on various scaffolds was quantitatively studied after 1,3 and 5 days of seeding using MTT (3- (4,5- dimethylthiazol- 2- yl)- 5- (3- carboxymethoxyphenyl)- 2- (4- sulfophenyl)- $2 \mathrm{H}$ - tetrazolium) assay. After each time point, the samples were washed with PBS solution, and MTT reagent $(100 \mu \mathrm{l})$ was added to each of the samples and incubated at $37^{\circ} \mathrm{C}$ for $4 \mathrm{~h}$. After incubation, the reaction was stopped by the addition of $200 \mu$ of sodium DMSO (dimethyl sulfoxide), and the absorbance was measured at $570 \mathrm{~nm}$ using multimode plate reader (Perkin Elmer (Ensight) multi-mode plate reader (HH34000000)).

\section{3) Cell Viability Assay}

Cell viability of cells seeded on scaffolds were assessed using live/dead assay which is a two-coloured fluorescent dye assay that differentially labels both live and dead cells. Stock solution of live/dead reagent was prepared by adding $4 \mu \mathrm{l}$ of EthD- 1 and $1 \mu \mathrm{l}$ of Calcein-AM in $2 \mathrm{ml}$ PBS. $100-150 \mu \mathrm{l}$ of live/dead reagent was added to the scaffolds on $3^{\text {rd }}$ day after seeding and incubated at room temperature for $1 \mathrm{~h}$. The well plate was observed under the fluorescence microscope (Nikon Eclipse-TE2000-U).

\section{4) Actin Filament Staining}

For actin cytoskeletal staining, the scaffolds were seeded with cells. Fixed after 3 days of culture with $4 \%$ paraformaldehyde for $30 \mathrm{~min}$, permeabilized using $0.3 \%$ triton -X 100 for $15 \mathrm{~min}$, blocked with $3 \%$ bovine serum albumin (BSA) for 30-40 min. The scaffolds were then incubated with rhodamine-phalloidin (1:200; Invitrogen) for $1 \mathrm{~h}$ at room temperature. All samples were then stained with DAPI (1:1000; HiMedia) for nuclear staining and imaged under fluorescence microscope (Nikon EclipseTE2000-U).

\section{5) Statistical Analysis}

All data are given as mean values with standard deviations. ANOVA was used to do statistical analysis. A $p$ value of $<0.05$ was deemed statistically significant, while a $p$ value of 0.01 was considered extremely significant $* p<0.05 ; * * p$ $<0.01 ;$ and $* * * p<0.001$.

\section{Results}

\section{Surface Morphology of Nanofibers by SEM}

To observe the roughness, fiber morphology and fiber quality, SEM analysis was done for PCL, aminolysed PCL (APCL) and maltose PCL (MPCL). It was observed that APCL and MPCL had similar morphology and it remained smooth and defect-free morphology like the PCL fibers (Fig.1).

Using image analysis tool (Image J, software), the diameter of the PCL nanofiber samples $(n=3)$ was calculated and found to be in the range of 200-950 nm, with a mean diameter of $650 \pm 200 \mathrm{~nm}$. Surface modification of PCL does not seem to be affecting the diameter of fibers. The measurement of interfiber size is known as pore size which is also calculated using ImageJ software. Table 1 shows the pore area distribution in between the total area of fibers.

Table 1 Porosity measurement in the SEM images

\begin{tabular}{llll}
\hline Sample & Magnification & Total area & Average pore area $(\mathrm{nm})$ \\
\hline PCL & 5000 & 725 & $28.91 \pm 1.63$ \\
APCL & 5000 & 725 & $36.75 \pm 2.23$ \\
MPCL & 5000 & 725 & $32.65 \pm 1.89$ \\
\hline
\end{tabular}



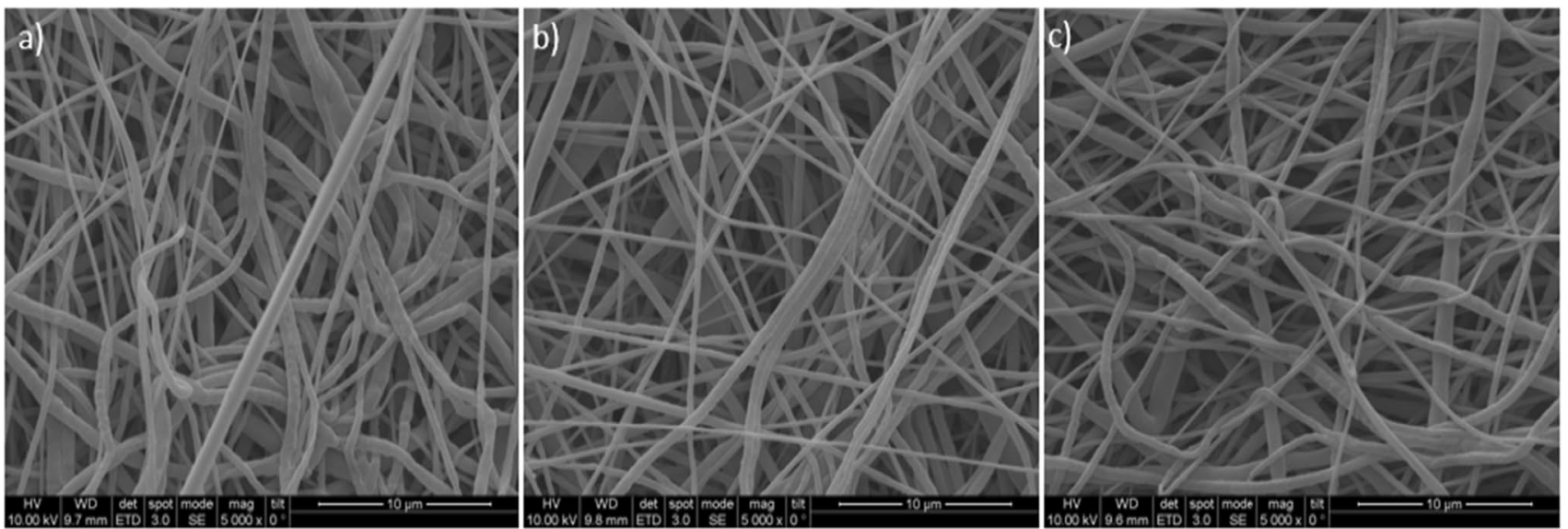

Fig. 1 Scanning electron microscopic images of (a) PCL, (b) APCL, and (c) MPCL

Fig. 2 FTIR spectra showing the peaks confirming aminolysis
FTIR- Spectra

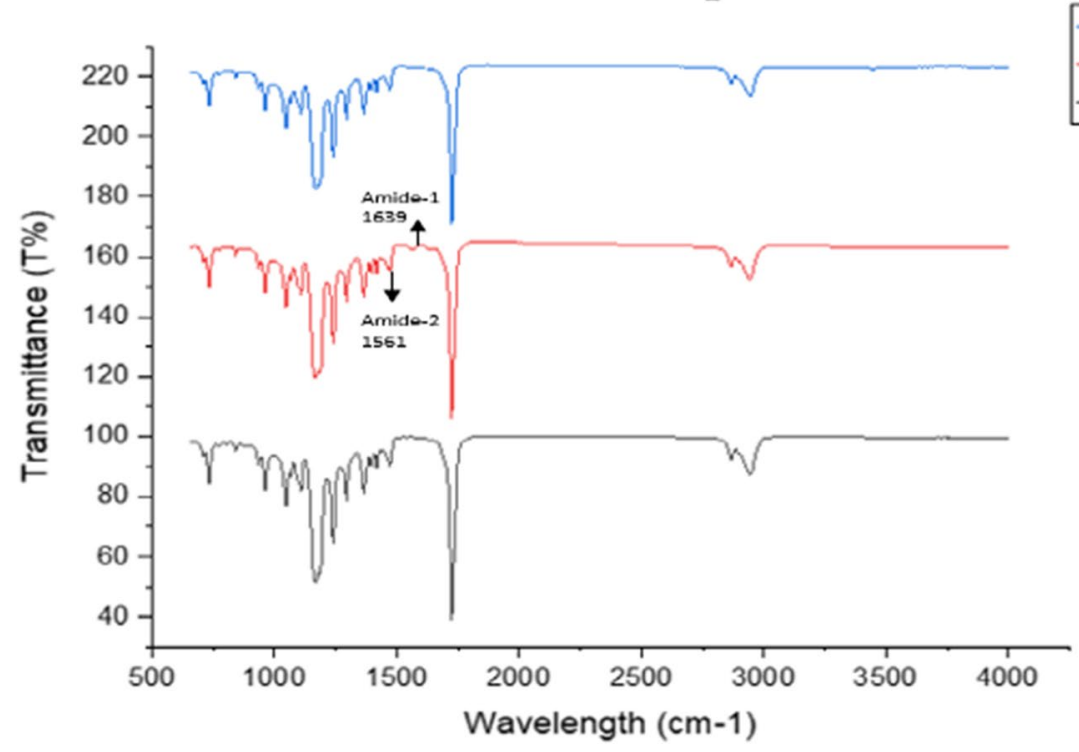

MPCL APCL PCL

\section{FTIR Analysis}

This was analysed for PCL, APCL and MPCL. This was analysed for the confirmation of modification by two-step wet chemistry method. From the results, it was observed that at a wavenumber of 1639 and $1561 \mathrm{~cm}^{-1}$, peak was seen in the aminolysed PCL which corresponds to the peak value of Amide 1 and Amide 2, respectively (Fig. 2).

\section{Amine Confirmation by Ninhydrin Assay}

The ninhydrin assay was quantified spectrophotometrically at $562 \mathrm{~nm}$. The results show that APCL scaffolds showed higher intensity than PCL- and maltose-bound PCL scaffolds. This was observed as the maltose conjugated on the amine groups do not have vacant sites for the ninhydrin

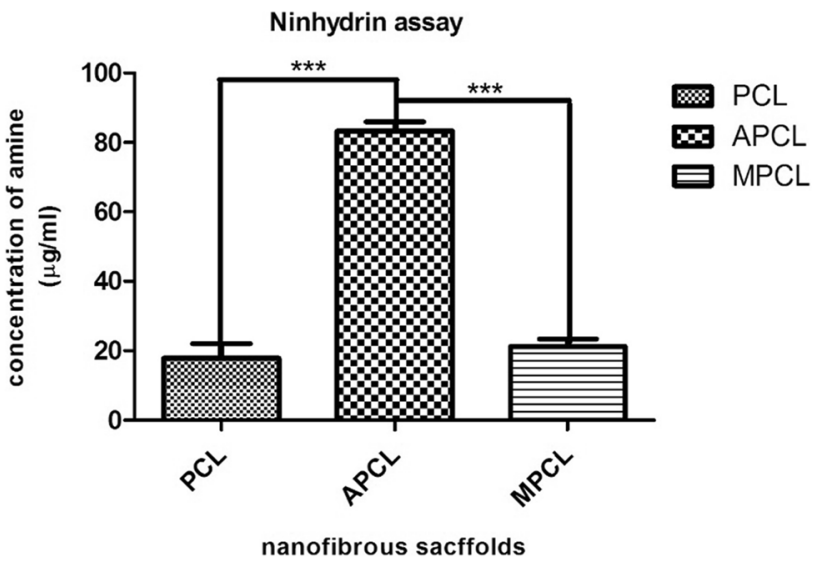

Fig. 3 Quantification of amine groups on PCL, APCL and MPCL 


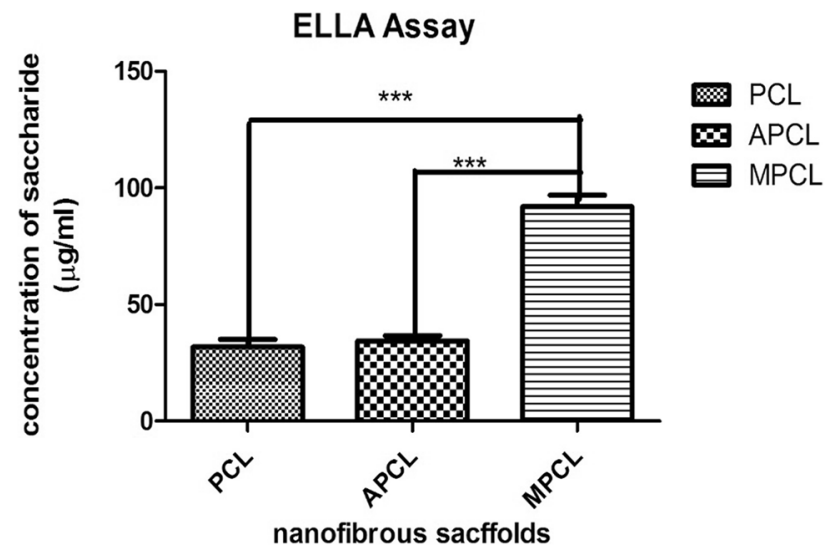

Fig. 4 Quantification of carbohydrate groups on PCL, APCL and MPCL

Table 2 Contact angle measurements

\begin{tabular}{lcc}
\hline Sample & Left angle $(\Theta)$ & Right angle $(\Theta)$ \\
\hline PCL & $124.18 \pm 2.3$ & $124.5 \pm 3.5$ \\
APCL & $97.91 \pm 0.6$ & $92.9 \pm 2.1$ \\
MPCL & $61.3 \pm 0.87$ & $72.6 \pm 4.3$ \\
\hline
\end{tabular}

molecules to bind to, leading to less intensity in MPCL scaffolds. Thus, confirming that the APCL scaffolds showed higher concentration of amine groups and maltose conjugation as well on the scaffolds (Fig. 3).

\section{ELLA Assay}

To analyse maltose moiety attachment to scaffolds, ELLA (enzyme linked lectin assay) was performed which was quantified spectrophotometrically which detects the specific carbohydrate units. The results showed that compared to PCL and APCL, MPCL showed more carbohydrate binding (Fig. 4).

\section{Contact Angle}

Table 2 Shows the contact angle of PCL, APCL and MPCL. Aminolysed PCL is showing lesser contact angle than the unmodified PCL, i.e. a reduction from $124^{\circ} \pm 2.3^{\circ}$ to $97^{\circ} \pm 1.6^{\circ}$ is observed. And maltose conjugated PCL showed further reduction in the contact angle i.e. to $61^{\circ} \pm 0.8^{\circ}$. It is clearly seen that MPCL is more hydrophilic than APCL and unmodified PCL showing that the modification had changed the surface wettability of the scaffolds to a greater extent (Fig. 5).

\section{Cell Adhesion and Proliferation Assay}

Cell proliferation was quantitatively assessed by MTT assay. All the scaffolds showed that they were compatible with the human uterine fibroblasts and showed better proliferation than tissue culture polystyrene dishes (TCPS). Aminolysed scaffolds although showed similar effect like the unmodified PCL on the 1st day, later showed superior proliferation rates of human uterine fibroblast (HUF) cells compared to the unmodified PCL scaffolds and TCPS after 3 and 5 days of culture. As expected, maltose-conjugated PCL scaffolds showed significantly higher proliferation rates over the TCPS, unmodified and APCL scaffolds at on all the time-points proving the HUF attachment and preference to carbohydrate moieties. Nonetheless, none of the scaffolds showed toxicity towards human uterine fibroblast cell culture indicating their cytocompatibility (Fig. 6).

\section{Cell Viability Assay}

To analyze the viability of scaffolds, a live/dead assay was also performed after 3 days of seeding and imaged by a fluorescence microscope. We observe that all the scaffolds were compatible with the HUFs as there were fewer dead cells on them compared to live cells and have no toxic effect on cells. Also, aminolysed and maltose modified scaffolds had shown better elongated morphology of HUFs cultured on

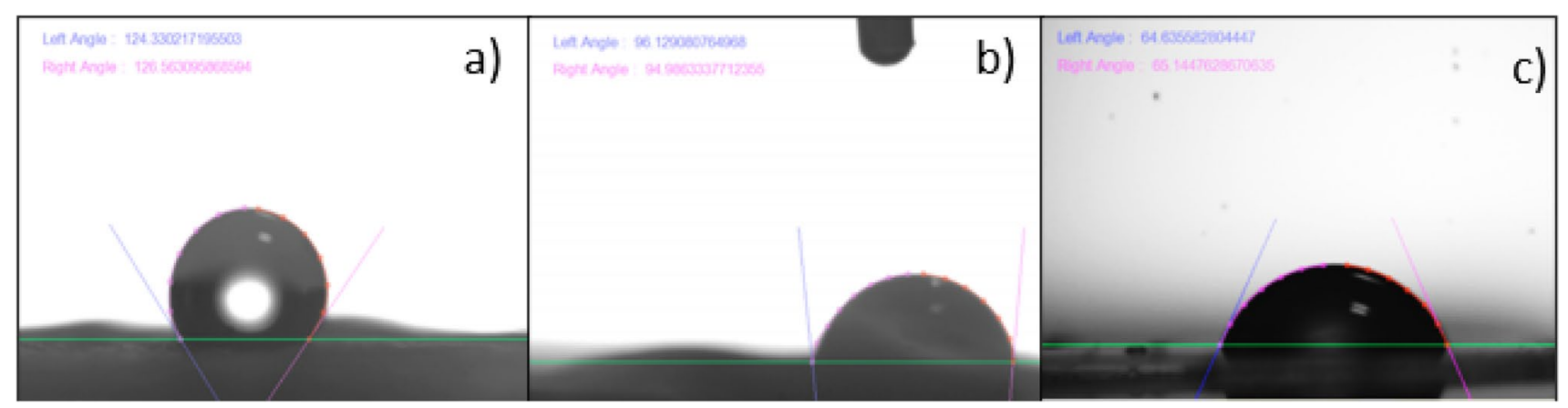

Fig. 5 Contact angle measurement on the (a) PCL, (b) APCL, and (c) MPCL 


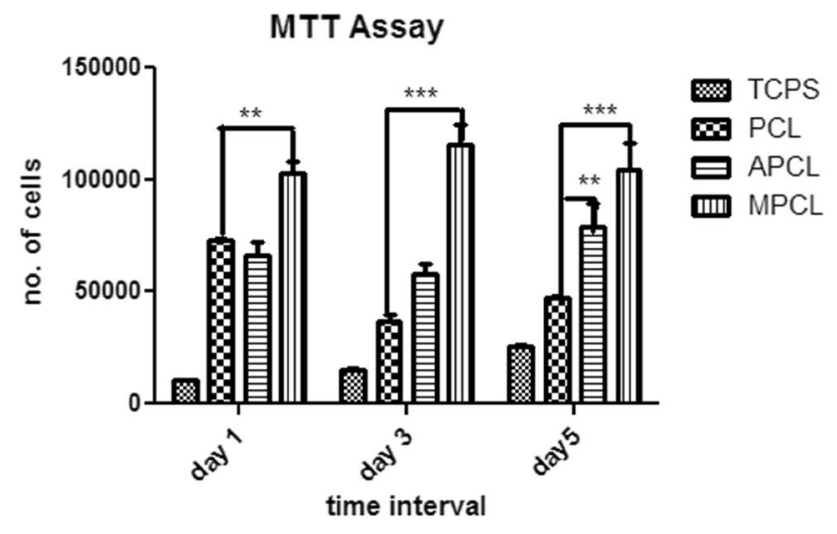

Fig. 6 MTT assay showing proliferation of HUF cells on the PCL, APCL and MPCL

them compared to TCPS due to the fibrous nature of scaffolds, and it was also observed that on the scaffolds, cells were incorporated inside than on their surface.

\section{Actin Staining}

To check the cellular morphology and their actin cytoskeletal arrangement on the modified scaffolds, the cells were stained with phalloidin after 3 days of seeding and imaged under a fluorescence microscope. The results showed that cells plated on PCL aggregated in one place and appeared to be growing on top of the other due to the hydrophobic nature of the scaffold, whereas cells plated on maltose-conjugated PCL were distributed and had intact morphology and better cytoskeletal arrangement than cells plated on other scaffolds.

\section{Discussion}

The prevalence of gynaecologic disorders has increased in the past few decades. However, the advanced treatments and medicines that are used to treat these are not very effective due to the complex nature of these tissues and the longterm side effects. Further advancements like transplantation of the uterus are highly rare due to the shortage of uteri donors. Therefore, we believe that the use of novel tissue engineering techniques to treat these would be highly beneficial. Uterine tissue engineering has received considerable attention over the years since uterus is the only place for the foetus to grow, and the need to develop a better method for regeneration of the uterine wall is of prime interest now. Majority of the research in this area have emphasised on the use of endometrial tissue in conjunction with collagen or matrigel scaffolds for uterine wall reconstruction [14-17]. Some of the studies provide evidence on the use of decellularized uterine tissue to mimic the architecture and functionality of the native tissue [18-21]. Few studies have also focused on the designing scaffolds for reconstruction of myometrial layer which is responsible for uterine contractions [22-24]. Renata et alet al. used synthetic polymer PGA/PLGA-based nanofibrous scaffolds seeded with rabbit autologous uterine cells and implanted in the excised uterine horn of rabbits which promoted uterus reconstruction and supported pregnancy [23]. In another study, a multicellular model of uterine wall based on PTFE synthetic membrane, collagen and matrigel layers with smooth muscle cells, endometrial epithelial cells and endometrial stromal cells was prepared to mimic the native uterus [24]. However, the use of synthetic polymers like PCL alone or in combination with other polymers for complete uterine tissue regeneration and organ reconstruction was not explored. Uterine wall is highly elastic made up of collagen fibrils which possibly helps the uterus to keep up its elasticity without applying abundance pressure on the developing embryo [25]. Since PCL polymer possesses elastic properties similar to the uterine wall muscle layer, we propose to use it as our base material to generate scaffolds in the current study to mimic the native tissue [26]. Therefore, the goal of the current study is to improve the uterine cell/tissue compatibility with biodegradable and mechanically superior scaffolds for uterine tissue regeneration, particularly the myometrial layer.

Carbohydrates take part in essential functions of the organisms such as cell interactions and communications. We used carbohydrates to modify the surface of the polymer. The use of glycomics for the study of cells is a novel technique. Elucidation of the complex interactions between specific polysaccharide and cells will be extremely valuable for the design of novel solutions to biological and chemical challenges. So far attempts have been made to incorporate functionalised scaffolds with carbohydrates such as in Anica Lancuški et al. (2013) [27]. They showed that bulk modification was not very effective whereas the surface-glycosylation of electrospun fibers showed better results. And in the study performed by Valeria Secchi et al. (2018) [12], it was shown that carbohydrates may positively influence the biocompatibility of PCL surfaces. In another study, it was validated that galactose attached on the surface of the scaffolds improves cell adhesion. The main idea behind carbohydrate modification on the scaffolds is that it increases L-selectin-based interaction of fibers with uterine cells. Therefore, L-selectingalactose binding leads to the activation of uterine fibroblasts which results in the remodeling of the extracellular matrix (ECM) [28]. To explore this further, we wanted to study the human uterine fibroblast cell behaviour on PCL unmodified and modified scaffolds.

Electrospinning is a comprehensive technique in producing nanofibrous polymer scaffolds, to optimize fibers produced by this method, various parameters have to be considered such as optimal voltage, collection distance, flow 
rate and solution viscosity through which we can obtain fibers that mimic the structural integrity of the native myometrial extracellular matrix (ECM) present in the uterus. Hence, we electrospun smooth and bead free PCL nanofibrous mats with average diameter of $650 \pm 200 \mathrm{~nm}$ and surface modified them following a two-step wet chemistry method. PCL fibres are hydrophobic in nature; therefore, they are modified using the two-step method to achieve a more controlled cell scaffold interaction by making them hydrophilic. The first step is aminolysis using 1,6 hexanediamine and introduction of $\mathrm{NH}_{2}$ groups onto PCL fibers which further help as attachment sites for maltose on the surface and makes the surface hydrophilic [29]. Contact angle results show that modified PCL scaffolds have shown hydrophilic behaviour than the unmodified PCL scaffolds. Moreover, MPCL has shown significant hydrophilicity than the APCL. Similarly, galactose-modified PCL substrates showed reduced water contact angle compared to unmodified scaffolds in other studies $[27,30]$. To confirm the presence of amine groups, ninhydrin assay was done. When the ninhydrin reagent interacts with the amine group on the surface, it turns dark purple, indicating the presence of the amine group, which is measured using a spectrophotometer at $562 \mathrm{~nm}$. In addition, $83.32 \pm 5.4 \mu \mathrm{g} / \mathrm{ml}$ of amine groups were generated on the surface of APCL nanofibers, while in MPCL, it was decreased to $21.2 \pm 6 \mu \mathrm{g} / \mathrm{ml}$. Similarly, another study found that following galactose modification, the amine group density on the PCL-Gal decreased from $2.42 \mathrm{~mol} / \mathrm{cm}^{2}$ to $1.89 \mathrm{~mol} / \mathrm{cm}^{2}$ [30]. These were later qualitatively analysed using FTIR which confirmed amide I and II stretching at 1639 and $1561 \mathrm{~cm}^{-1}$ respectively. Maltose modification was performed on the scaffolds and an ELLA assay was performed on them for the confirmation of presence of saccharide moiety on the surface. We quantified the amount of lectin conjugated on the surface with sugar which is directly proportional to the amount of sugar, and it is found to be $91.02 \pm 1.4 \mu \mathrm{g} / \mathrm{ml}$. In other studies, galactose [30]- and mannose-conjugated PCL substrates also showed similar behaviour [27].
From cell culture results, it is indicated that maltose modified scaffolds showed significantly higher proliferation of cells when compared to APCL and PCL. In the current study, we have used TCPS as a control or reference to understand the cytocompatibility of modified PCL substrates with the uterine fibroblasts. In MTT assay, all the PCL nanofibrous scaffolds have shown significantly higher proliferation rates than the TCPS indicating that the fibrous morphology has an important role in influencing the proliferation. Also APCL had shown higher proliferation rates than the TCPS and unmodified PCL after 3 and 5 days of culture. Similarly, in a study, Schwann cells had better proliferation and attachment on aminolysed PCL films [31]. Prominent observation is that maltose-conjugated PCL had shown significantly higher proliferation rates than all other scaffolds at all the time points. Similar to our work, neuroblastoma F11 cells have shown higher proliferation rates on maltose conjugated and aminolysed PCL than unmodified PCL films [12]. Also in another study, galactose-modified PCL molds have exhibited superior cell spreading and density than unmodified PCL [30]. In the live dead assay in Fig. 7, cells are more elongated and stretched on the MPCL and APCL scaffolds compared to the TCPS and PCL. It was also observed that there were fewer dead cells on all the nanofibrous scaffolds indicating their cytocompatibility. Actin staining was also done to determine the cytoskeletal spreading and morphology of the cells on the scaffolds. It was shown that HUFs were aggregated in one place in unmodified PCL probably because of its hydrophobic nature, whereas APCL and MPCL scaffolds being hydrophilic in nature have retained and showed elongated morphology (Fig. 8). However, the HUF morphology on TCPS and MPCL looks almost similar showing that they are moderately comparable with each other. This is due to the fact that each type of a cell responds differently to diverse scaffold geometries, topography and surface chemistries [32]. For example, in a study, L929 fibroblast attachment was better on fibrous and film scaffolds, whereas RT4D6P2T Schwann cells was better on TCPS indicating that the L929 cells prefer rough surfaces and RT4-D6P2T cells
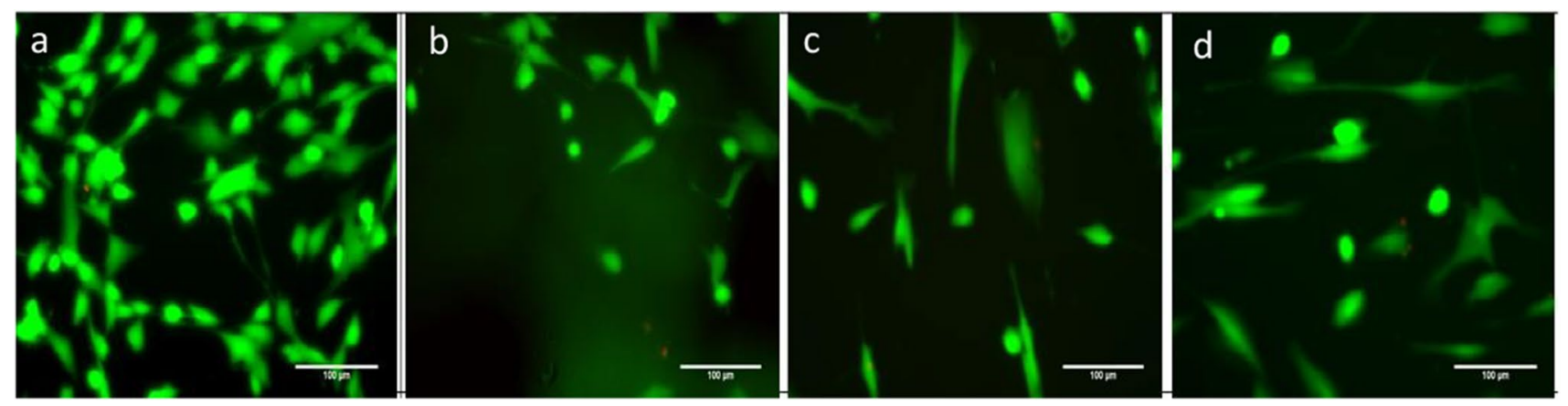

Fig. 7 Live/dead assay with human uterine fibroblast cells seeded on (a) TCPS, (b) PCL, (c) APCL and (d) MPCL scaffolds 

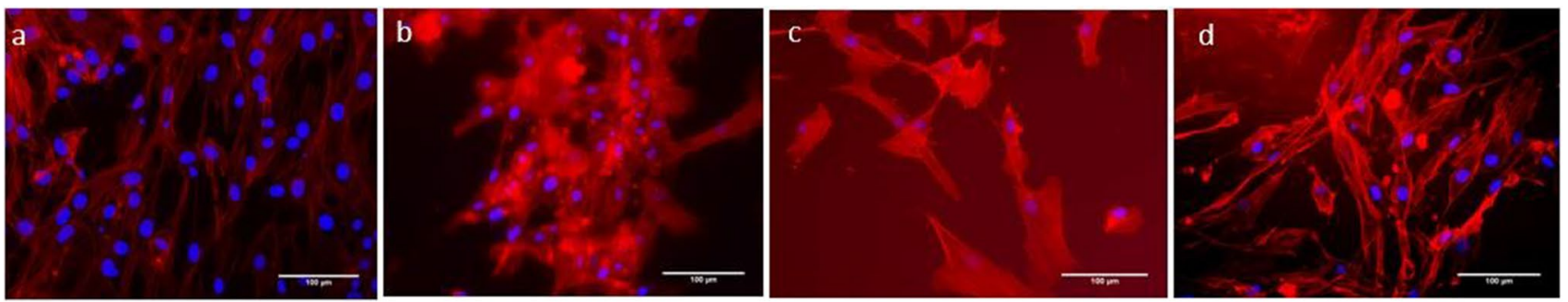

Fig. 8 Actin staining of Human uterine fibroblast cells on (a) TCPS, (b) PCL, (c) APCL and (d) MPCL scaffolds

prefer flat surfaces [33]. However, uterine fibroblast interaction with PCL nanofibrous substrates was not studied earlier. So the current observations along with the future studies planned with gene and protein expression analysis would give us a better understanding of these aspects.

Therefore, based on the above results, maltose-modified PCL scaffolds could be used as potential substrates for uterine tissue engineering. In the future objectives of this project, the role of maltose in the remodelling of the uterine ECM and compatibility of the scaffolds with human uterine smooth muscle cells will be evaluated. These novel substrates could also be used to treat uterine defects and reconstruct the complete uterus which can be assessed in suitable pre-clinical models.

\section{Conclusion}

PCL nanofibers were successfully surface modified using aminolysis and maltose was conjugated on the surface. The modification was confirmed using contact angle, ninhydrin assay and ELLA assay. The hydrophilicity of the scaffolds increased significantly on the APCL and MPCL scaffolds. Amine groups were quantified on the APCL by ninhydrin assay. Maltose moieties were confirmed on the MPCL scaffolds by ELLA assay. Human uterine fibroblasts were compatible with PCL, aminolysis PCL, and maltose-conjugated PCL scaffolds. MPCL scaffolds showed significantly higher proliferation and better morphology of the HUF cells compared to the other scaffolds. Hence the maltose-modified PCL nanofibers could be used as potential substrates for uterine tissue engineering.

Acknowledgements The authors would like to acknowledge the Department of Science \& Technology for the SERB start-up research grant (SRG/2019/002130) for financial support. We would also like to thank MAHE intramural grant (MAHE/DREG/PHD/IMF/2019) and Dr T.M.A. Pai Ph.D. Scholarship respectively from Manipal Academy of Higher Education. We also would extend thanks to the Manipal Institute of Regenerative Medicine, MAHE for the infrastructural support.
Authors' Contributions SH has performed the experiments and prepared the manuscript figures. MN has designed the experiments and prepared the manuscript draft.

Funding The authors would like to acknowledge the Department of Science \& Technology for the SERB startup research grant (SRG/2019/002130) for financial support. We would also like to thank MAHE intramural grant (MAHE/DREG/PHD/IMF/2019) and Dr T.M.A. Pai Ph.D. Scholarship respectively from Manipal Academy of Higher Education.

Availability of Data and Material Not applicable.

Code Availability Not applicable.

\section{Declarations}

Ethics Approval Not applicable.

Consent to Participate Not applicable.

FIGConsent for Publication Not applicable.

Conflict of Interest The authors declare they have no competing interests.

Open Access This article is licensed under a Creative Commons Attribution 4.0 International License, which permits use, sharing, adaptation, distribution and reproduction in any medium or format, as long as you give appropriate credit to the original author(s) and the source, provide a link to the Creative Commons licence, and indicate if changes were made. The images or other third party material in this article are included in the article's Creative Commons licence, unless indicated otherwise in a credit line to the material. If material is not included in the article's Creative Commons licence and your intended use is not permitted by statutory regulation or exceeds the permitted use, you will need to obtain permission directly from the copyright holder. To view a copy of this licence, visit http://creativecommons.org/licenses/by/4.0/.

\section{References}

1. Rosner J, Samardzic T, Sarao MS. Physiology, female reproduction. In: Female reproduction, n: StatPearls [Internet]. Treasure Island (FL): StatPearls Publishing; 2021.

2. Wang N, Zhang Y, Liu B. Demographic and Clinical Features of Endometrial Polyps in Patients with Endometriosis. Biomed Res Int. 2016;2016:1-5. https://doi.org/10.1155/2016/1460793. 
3. Eltom A, Zhong G, Muhammad A. Scaffold Techniques and Designs in Tissue Engineering Functions and Purposes: A Review. Adv Mater Sci Eng. 2019;2019:1-13. https://doi.org/10. 1155/2019/3429527.

4. Norian JM, Owen CM, Taboas J, Korecki C, Tuan R, Malik M, Catherino WH, Segars James H. Characterization of tissue biomechanics and mechanical signaling in uterine leiomyoma. Matrix Biol. 2012;31(1):57-65. https://doi.org/10.1016/j.matbio.2011.09. 001.

5. Baker SR, Banerjee S, Bonin K, Guthold M. Determining the mechanical properties of electrospun poly- $\varepsilon$-caprolactone (PCL) nanofibers using AFM and a novel fiber anchoring technique. Mater Sci Eng C. 2016;59:203-12. https://doi.org/10.1016/j.msec. 2015.09.102.

6. Pearsall GW, Roberts VL. Passive mechanical properties of uterine muscle (myometrium) tested in vitro. J Biomech. 1978;11(4):16776. https://doi.org/10.1016/0021-9290(78)90009-X.

7. Tang M, Purcell M, Steele§ JAM, Lee K-Y, McCullen S, Shakesheff KM, Bismarck A, Stevens MM, Howdle SM, Williams CK. Porous copolymers of $\varepsilon$-caprolactone as scaffolds for tissue engineering. Macromolecules. 2013;46(20):8136-43. https://doi.org/ 10.1021/ma401439z.

8. Mochane MJ, Motsoeneng TS, Sadiku ER, Mokhena TC, Sefadi JS. Morphology and properties of electrospun PCL and its composites for medical applications: A mini review. Appl Sci. 2019;9(11):1-17. https://doi.org/10.3390/app9112205.

9. Perić Kačarević, Željka, Patrick Rider, Said Alkildani, Sujith Retnasingh, Marija Pejakić, Reinhard Schnettler, Martin Gosau, Ralf Smeets, Ole Jung, and Mike Barbeck. An introduction to bone tissue engineering. Int J Artif Organs. 2020;43(2):69-86. https:// doi.org/10.1177/0391398819876286.

10. Yoo HS, Kim TG, Park TG. Surface-functionalized electrospun nanofibers for tissue engineering and drug delivery. Adv Drug Deliv Rev. 2009;61(12):1033-42. https://doi.org/10.1016/j.addr. 2009.07.007.

11 Clark GF. Functional glycosylation in the human and mammalian uterus. Fertil Res Pract. 2015;1(1):1-12. https://doi.org/10.1186/ s40738-015-0007-0.

12. Valeria Secchi, Roberto Guizzardi, Laura Russo, Valentina Pastori, Marzia Lecchi, Stefano Franchi, Giovanna Iucci. Maltose conjugation to PCL: Advanced structural characterization and preliminary biological properties. J Mol Struct. 2018;1159:74-8. https://doi.org/10.1016/j.molstruc.2018.01.051.

13. Powell JK, Glasser SR, Woldesenbet S, Burghardt RC, Newton GR. Expression of carbohydrate antigens in the goat uterus during early pregnancy and on steroid-treated polarized uterine epithelial cells in vitro. Biol Reprod. 2000;62(2):277-84. https://doi.org/10. 1095/biolreprod62.2.277.

14. Song T, Zhao X, Sun H, Li X, Lin N, Ding L, Dai J, Hu Y. Regeneration of uterine horns in rats using collagen scaffolds loaded with human embryonic stem cell-derived endometrium-like cells. Tissue Eng - Part A. 2015;21(1-2):353-61. https://doi.org/10. 1089/ten.tea.2014.0052.

15. Ding L, Li X, Sun H, Su J, Lin N, Péault B, Song T, Yang J, Dai J, Hu Y. Transplantation of bone marrow mesenchymal stem cells on collagen scaffolds for the functional regeneration of injured rat uterus. Biomaterials. 2014;35(18):4888-900. https://doi.org/10. 1016/j.biomaterials.2014.02.046.

16. Xu L, Ding L, Wang L, Cao Y, Zhu H, Lu J, Li X, Song T, Hu Y, Dai J. Umbilical cord-derived mesenchymal stem cells on scaffolds facilitate collagen degradation via upregulation of MMP-9 in rat uterine scars. Stem Cell Res Ther. 2017;8(1):1-13. https:// doi.org/10.1186/s13287-017-0535-0.

17. Lü SH, Wang HB, Liu H, Wang HP, Lin QX, Li DX, Song YX, Duan CM, Feng LX, Wang CY. Reconstruction of engineered uterine tissues containing smooth muscle layer in collagen/ matrigel scaffold in vitro. Tissue Eng Part A. 2009;15(7):1611-8. https://doi.org/10.1089/ten.tea.2008.0187.

18. Arezoo N, Mohammad H, Malihezaman M. Tissue engineering of mouse uterus using menstrual blood stem cells ( MenSCs ) and decellularized uterine scaffold. Stem Cell Res Ther. 2021;12(1):112. https://doi.org/10.1186/s13287-021-02543-y.

19. Santoso EG, Yoshida K, Hirota Y, Aizawa M, Yoshino O, Kishida A, Osuga Y, Saito S, Ushida T, Furukawa KS. Application of detergents or high hydrostatic pressure as decellularization processes in uterine tissues and their subsequent effects on in vivo uterine regeneration in murine models. PLoS One. 2014;9(7):e103201. https://doi.org/10.1371/journal.pone.01032 01.

20. Miyazaki K, Maruyama T. Partial regeneration and reconstruction of the rat uterus through recellularization of a decellularized uterine matrix. Biomaterials. 2014;35(31):8791-800. https://doi. org/10.1016/j.biomaterials.2014.06.052.

21. Tiemann TT, Padma AM, Sehic E, Bäckdahl H, Oltean M, Song MJ, Brännström M, Hellström M. Towards uterus tissue engineering: a comparative study of sheep uterus decellularisation. Mol Hum Reprod. 2020;26(3):167. https://doi.org/10.1093/MOLEHR/ GAAA009.

22. Young RC, Goloman G. Allo- and xeno-reassembly of human and rat myometrium from cells and scaffolds. Tissue Eng - Part A. 2013;19(19-20):2112-9. https://doi.org/10.1089/ten.tea.2012. 0549 .

23. Magalhaes RS, Williams JK, Yoo KW, Yoo JJ, Atala A. A tissueengineered uterus supports live births in rabbits. Nat Biotechnol. 2020;38(11):1280-7. https://doi.org/10.1038/s41587-020-0547-7.

24. Kuperman, Tatyana \& Gavriel, Mark \& Gotlib, Ruth \& Zhang, Ying \& Jaffa, Ariel \& Elad, David \& Grisaru, Dan. Tissue-engineered multi-cellular models of the uterine wall. Biomech Model Mechanobiol. 2020;19(5):1629-39. https://doi.org/10.1007/ s10237-020-01296-6.

25. Leppert PC, Yu SY. Three-dimensional structures of uterine elastic fibers: scanning electron microscopic studies. Connect Tissue Res. 1991;27(1):15-31.

26. Kurniawan D, Nor FM, Lee HY, Lim JY. Elastic properties of polycaprolactone at small strains are significantly affected by strain rate and temperature. Proc Inst Mech Eng Part H J Eng Med. 2011;225(10):1015-20. https://doi.org/10.1177/0954411911 413059.

27. Lancuški A, Bossard F, Fort S. Carbohydrate-decorated PCL fibres for specific protein adhesion. Biomacromolecules. 2013;14(6):1877-84. https://doi.org/10.1021/bm400263d.

28. Genbacev OD, Prakobphol A, Foulk RA, Krtolica AR, Ilic D, Singer MS, Yang ZQ, Kiessling LL, Rosen SD, Fisher SJ. Trophoblast L-selectin-mediated adhesion at the maternal-fetal interface. Science. 2003;299(5605):405-8. https://doi.org/10.1126/science. 1079546.

29. Zhu Y, Gao C, Liu X, Shen J. Surface modification of polycaprolactone membrane via aminolysis and biomacromolecule immobilization for promoting cytocompatibility of human endothelial cells. Biomacromol. 2002;3(6):1312-9. https://doi.org/10.1021/ bm020074y.

30. Russo L, Russo T, Battocchio C, Taraballi F, Gloria A, D'Amora U, De Santis R, Polzonetti G, Nicotra F, Ambrosio L, Cipolla L. Galactose grafting on poly( $\varepsilon$-caprolactone) substrates for tissue engineering: a preliminary study. Carbohydr Res. 2015;405:3946. https://doi.org/10.1016/j.carres.2014.07.027

31. de Luca AC, Terenghi G, Downes S. Chemical surface modification of poly-e-caprolactone improves Schwann cell proliferation for peripheral nerve repair. Ann Am Thorac Soc. 2012;12(6):1312-9. https://doi.org/10.1021/bm020074y.

32 Kaniuk Ł, Krysiak ZJ, Metwally S, Stachewicz U. Osteoblasts and fibroblasts attachment to poly(3-hydroxybutyric 
acid-co-3-hydrovaleric acid) (PHBV) film and electrospun scaffolds. Mater Sci Eng C. 2020;110(January):110668. https://doi. org/10.1016/j.msec.2020.110668.

33. Suwantong O, Waleetorncheepsawat S, Sanchavanakit N, Pavasant P, Cheepsunthorn P, Bunaprasert T, Supaphol P. In vitro biocompatibility of electrospun poly(3-hydroxybutyrate) and poly(3-hydroxybutyrate-co-3-hydroxyvalerate) fiber mats. Int J Biol Macromol. 2007;40(3):217-23. https://doi.org/10.1016/j. ijbiomac.2006.07.006
Publisher's Note Springer Nature remains neutral with regard to jurisdictional claims in published maps and institutional affiliations. 